AperTO - Archivio Istituzionale Open Access dell'Università di Torino

A case of nonfatal intoxication associated with the recreational use of diphenidine

This is a pre print version of the following article:

Original Citation:

Availability:

This version is available http://hdl.handle.net/2318/1657787

since 2018-01-16T17:38:35Z

Published version:

DOI:10.1111/1556-4029.13355

Terms of use:

Open Access

Anyone can freely access the full text of works made available as "Open Access". Works made available under a Creative Commons license can be used according to the terms and conditions of said license. Use of all other works requires consent of the right holder (author or publisher) if not exempted from copyright protection by the applicable law. 


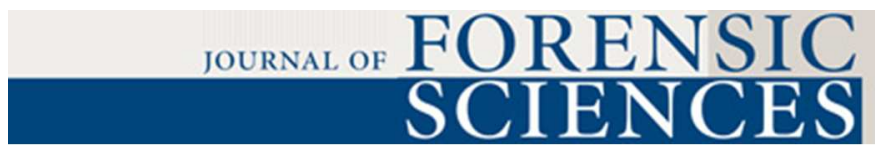

\section{A case of non-fatal intoxication associated with the recreational use of diphenidine}

\begin{tabular}{|r|l|}
\hline Journal: & Journal of Forensic Sciences \\
\hline Manuscript ID & JOFS-16-204 \\
\hline Danuscript Type: & Case Report \\
\hline Complete List of Authors: & $\begin{array}{l}\text { Gerace, Enrico; Centro Regionale Antidoping "A. Bertinaria", } \\
\text { Bovetto, Elena; ASL TO5, Ospedale Maggiore , Dipartimento di Anestesia e } \\
\text { Rianimazione } \\
\text { Di Corcia, Daniele; Centro Regionale Antidoping "A. Bertinaria" } \\
\text { Vincenti, Marco; Centro Regionale Antidoping "A. Bertinaria"; Universita } \\
\text { degli Studi di Torino, Dipartimento di Chimica } \\
\text { Salomone, Alberto; Centro Regionale Antidoping "A. Bertinaria" }\end{array}$ \\
\hline Keywords: & $\begin{array}{l}\text { Forensic science, Diphenidine, Dissociative drugs, New psychoactive } \\
\text { substances, Intoxication, Designer drugs }\end{array}$ \\
\hline \multicolumn{2}{|c}{} \\
\hline
\end{tabular}

SCHOLARONE ${ }^{\mathrm{m}}$

Manuscripts 


\title{
A case of non-fatal intoxication associated with the recreational use of diphenidine
}

Enrico Gerace $^{1 *}$, Elena Bovetto $^{2}$, Daniele Di Corcia $^{1}$, Marco Vincenti ${ }^{1,3}$ and Alberto Salomone ${ }^{1}$

${ }^{1}$ Centro Regionale Antidoping “A. Bertinaria”, Regione Gonzole 10/1, 10043 Orbassano, Turin, Italy

${ }^{2}$ ASL TO5, Ospedale Maggiore - Dipartimento di Anestesia e Rianimazione, Via De Maria 1, 10023 Chieri, Turin, Italy

${ }^{3}$ Dipartimento di Chimica, Università degli Studi di Torino, via P. Giuria 7, 10125 Turin, Italy

\begin{abstract}
*Corresponding author: Enrico Gerace, $\mathrm{PhD}$
Centro Regionale Antidoping “A. Bertinaria”,

Regione Gonzole, 10/1 - 10043 Orbassano (Turin) - Italy

Tel: +3901190224249 , Fax: +3901190224242 , Mobile: +393393795125

E-mail address: enrico.gerace@antidoping.piemonte.it
\end{abstract}

Keywords: Forensic science; Diphenidine; Dissociative drugs; New psychoactive substances, Intoxication; Designer drugs. 


\section{ABSTRACT}

Diphenidine is a dissociative drug commonly sold online as research chemical. Several psychotropic effects can appear during diphenidine intoxication including euphoria, shifts in perception of reality, hallucinations and transient anterograde amnesia.

In this study, we report a case of acute intoxication occurring after diphenidine intake.

A 30-year-old Caucasian male was hospitalized after he was found in a confused and agitated state, and unable to communicate. The physical examination displayed tachycardia, miotic pupils and increased body temperature and respiratory rate. GC/MS analysis revealed the presence of diphenidine in plasma and urine at concentrations of 308 and $631 \mathrm{ng} / \mathrm{mL}$, respectively. Plasma analysis also revealed the presence of methylphenidate and diclazepam. The clinical progress of the patient was favourable and his symptoms were cured with a symptomatic treatment.

The combined circumstantial elements and toxicological results of the case reported revealed the occurrence of an acute intoxication ascribable to the recreational abuse of diphenidine. 
Diphenidine (1-(1,2-diphenylethyl)piperidine) is a dissociative anaesthetic designer drug structurally related to arylcyclohexylamines like phencyclidine (PCP), ketamine and methoxetamine (MXE) (1). Diphenidine was first synthesized in 1924 and studied as a neuroprotective agent for the treatment of brain injury following hypoxia (2). Diphenidine can act as N-methyl-D-aspartate (NMDA) receptor antagonists, serotonin transporter inhibitors, dopamine agonists and opioid agonist, producing dissociative effects similar to those induced by ketamine and MXE $(1,3)$. For this reason, diphenidine and its analogues are candidated to be used as a recreational drug, mainly among users of new psychoactive substances. All these drugs are available from internet suppliers and sold as research chemicals 'not for human consumption'(4). Diphenidine is generally sold as white or slightly yellowish powder or fine crystals. The most common routes for recreational intake, reported by drug users in web discussion forums, are nasal insufflation (snorting) and oral ingestion (3). Due to the fact that this drug is not used for medical purposes, the information about its pharmacology, side-effects, and toxicology are very limited. In the reports collected on web forums, diphenidine use is associated with strong dissociative effects starting at oral doses of $110 \mathrm{mg}$ and higher doses inducing bizarre somatosensory phenomena and transient anterograde amnesia, lasting for $3-6 \mathrm{~h}(1)$.

Recently, Helander et al. described a series of 17 cases of intoxication due to the consumption of diphenidine and methoxphenidine (5). The commonly recorded clinical features were hypertension, tachycardia, anxiety, and altered mental status including confusion, disorientation, dissociation, and/or hallucinations. The same symptoms were reported by Hofer et al. in an intoxication case associated to the use of methoxphenidine (6). A case of acute and lethal intoxication related to the simultaneous consumption of the synthetic cannabinoids AB-CHMINACA, 5-fluoro-AMB and diphenidine were also reported in literature (7). In another study, the post-mortem distribution of these drugs in body fluids and solid tissues was studied and similar cases of acute or fatal intoxication associated with the use of the methoxy-analog of diphenidine, namely 2-methoxydiphenidine, were recently reported (8). However, little is still known about the correlation between 
the blood concentration of these compounds and their effects. In this paper, we report a case of acute toxicity after diphenidine intake, in association with other psychoactive substances. The presence of the drug was confirmed in plasma and urine by means of mass spectrometry-based chromatographic methods.

\section{Case Report}

A 30-year-old Caucasian man with previous history of drug addiction was found seated alongside his bed in a confused and agitated state, and unable to communicate. On the floor, a small plastic bag was found, containing few milligrams of a white powder labelled 'Diphenidine 1g'. The content of the plastic bag was analytically confirmed by gas chromatography-mass spectrometry. No current medication was declared to the rescue unit by the subject's relatives. The first physical examination revealed tachycardia (heart rate $160 \mathrm{bpm}$ ), and miotic nonreactive pupils. The preliminary medical examination also verified a state of agitation, disorientation and altered consciousness with a Glasgow Coma Scale (GCS) of 9. Midazolam (30 mg intravenously, divided in repeated injections at increasing dosages) was initially administered for sedation. No traces of vomit were found. On arrival at the emergency department, the patient was still agitated and uncontrollable, with major muscular rigidity. The physical examination displayed tachycardia (160 bpm), tachypnea and miotic pupils. The external body temperature recorded was $38.0^{\circ} \mathrm{C}$. Blood gas analysis revealed severe metabolic acidosis with blood $\mathrm{pH} 7.17$ (reference 7.35-7.45), base excess (BE) of $-14 \mathrm{mmol} / \mathrm{L}$ (reference from -2 to $+2 \mathrm{mmol} / \mathrm{L}$ ) and lactate concentration of $13 \mathrm{mEq} / \mathrm{L}$ (reference $<4 \mathrm{mEq} / \mathrm{L}$ ). The patient was treated for sedation with midazolam (15 mg intravenously), diazepam (10 mg intravenously), chlorphenamine maleate (10 mg intravenously), haloperidol (2 mg intravenously) and sodium bicarbonate $5 \% \mathrm{~m} / \mathrm{v}(250 \mathrm{~mL}$ intravenously). After $90 \mathrm{~min}$, the patient regained consciousness but his speech was still drowsy and slowed. His pupils were still miotic but no amnesia phenomenon was reported. The ECG and the respiratory rate were normal, while the 
body temperature was around $37.0^{\circ} \mathrm{C}$. The patient admitted to have taken the diphenidine powder by nasal insufflations about five hours before the rescuer arrival at his home. Twelve hours after the hospitalization, laboratory analysis revealed an increase of creatine kinase (CK: $87923 \mathrm{U} / \mathrm{L}$; reference $<190 \mathrm{U} / \mathrm{L}$ ), alanine aminotransferase (ALT: $77 \mathrm{U} / \mathrm{L}$; reference $<40 \mathrm{U} / \mathrm{L}$ ), aspartate aminotransferase (AST: $500 \mathrm{U} / \mathrm{L}$; reference < $37 \mathrm{U} / \mathrm{L}$ ), and lactate dehydrogenase (LDH: $4908 \mathrm{U} / \mathrm{L}$; reference 240-480 U/L) indicating rhabdomiolysis. After two hours, the blood pressure was reverted to $115 / 70 \mathrm{mmHg}$, with an heart rate of $88 \mathrm{bpm}$ and a body temperature back to $36.6{ }^{\circ} \mathrm{C}$. Twelve hours after arrival at the Emergency Department, the patient was relaxed and drowsy, but easily aroused by verbal stimulation. His blood pressure was stable at $125 / 70 \mathrm{mmHg}$, with an heart rate of $65 \mathrm{bpm}$. After 5 days of observation, the patient was discharged. CK, ALT, AST and LDH trends recorded during the hospitalization period are shown in Figure 1. Blood and urine samples were collected on admission and submitted to the laboratory for toxicological analyses. Moreover, an hair lock sample was collected as additional matrix and tested for the presence of several new psychoactive substances with stimulant, psychedelic, and dissociative properties.

\section{Toxicological analysis}

Immunochemical toxicology screening on urine was performed by Enzyme Multiplied Immunoassay Technique (EMIT, Abbott Laboratories, IL, USA) and turned out positive for benzodiazepines and cannabinoids, and negative for cocaine, amphetamine, opioids, barbiturates, methadone, tricyclic antidepressants, 3,4-methylenedioxymethamphetamine and methamphetamines. Screening analysis for unknown substances was performed in urine, plasma (both extracted with TBME at alkaline conditions) and the powder found beside the patient at his home by gas chromatography/mass spectrometry. Full scan spectra in the interval 40-650 amu were acquired using a 5975 inert mass-selective detector (Agilent Technologies, Milan, Italy) operating in the EI mode at $70 \mathrm{eV}$. The qualitative identification of the compounds was performed by 
comparing the full scan spectra obtained with those recorded in the updated spectra libraries (PMWTox2, SWGDRUG version 1.7, AAFS2012, CaymanSpectraLib). For the diphenidine confirmation analysis, a dedicated GC-MS procedure was developed. A 6890N gas chromatograph from Agilent Technologies (Milan, Italy) equipped with a J\&W HP-5 capillary column, $17 \mathrm{~m} \times$ $0.200 \mathrm{~mm} \times 0.33 \mu \mathrm{m}$ was used. Helium was employed as the carrier gas at a constant pressure of 30.00 psi. The $\mathrm{GC}$ oven temperature was set at $90^{\circ} \mathrm{C}$ for $1 \mathrm{~min}$ and then raised to $180^{\circ} \mathrm{C}$ with a $30^{\circ} \mathrm{C} / \mathrm{min}$ heating rate. The oven temperature was maintained at $180{ }^{\circ} \mathrm{C}$ for $7 \mathrm{~min}$ and then raised to $315^{\circ} \mathrm{C}$ with a $15^{\circ} \mathrm{C} / \mathrm{min}$ heating rate. The total run time was $23 \mathrm{~min}$. The $\mathrm{GC}$ injector and transfer line were maintained at $280^{\circ} \mathrm{C}$.

The chromatograph was coupled to a 5975-inert MSD from Agilent Technologies (Milan, Italy) with EI at $70 \mathrm{eV}$. Quantitative determination of diphenidine was performed by monitoring the diagnostic ions at m/z 174 (target ion), 175 and 91 (qualifiers), whereas for the internal standard (ethaverine), the diagnostic ions at $\mathrm{m} / \mathrm{z} 366,280$ and 394 were chosen.

Other confirmation analyses on blood, urine and hair were performed by means of updated liquid chromatography/tandem-mass spectrometry (LC/MS-MS) methods routinely employed in our laboratory $(9,10,11,12)$.

\section{Results}

Diphenidine was identified as the only component of the powder. The same compound was quantified in plasma and urine specimens at concentrations of $308 \mathrm{ng} / \mathrm{mL}$ and $631 \mathrm{ng} / \mathrm{mL}$, respectively. Moreover, diphenidine was detected in hair sample at $4400 \mathrm{pg} / \mathrm{mg}$ concentration. Other findings included $\alpha$-PVP (1040 pg/mg), MDPV (120 pg/mg), methoxetamine (27 pg/mg), 4fluoroamphetamine $(55 \mathrm{pg} / \mathrm{mg})$ and methylone (traces). Several other drugs were quantitatively determined in plasma, some of which had been administered in hospital. These included benzodiazepines such as diazepam, nordiazepam, delorazepam (chlordesmethyldiazepam), 
lormetazepam, lorazepam and midazolam, together with haloperidol and methylphenidate. Moreover, the designer benzodiazepine diclazepam was also found in the patient's plasma sample at a concentration of $3.5 \mathrm{ng} / \mathrm{mL}$. All the findings in plasma and urine samples are summarized in Table 1.

\section{Discussion}

Dissociative drugs distort perceptions of sight and sound and produce feelings of detachment (or dissociation) from the environment and self. Among the dissociative drugs, ketamine and phencyclidine (PCP) are the drugs most commonly used for recreational purpose. In the last 5 years, a new generation of synthetic dissociative drugs appeared on the market, including methoxethamine (MXE), methoxphenidine, diphenidine and phencyclidine derivatives (e.g. 4-MeOPCP), which have rapidly spreaded as a legal replacements for the banned ketamine and PCP (1). The introduction of new psychoactive drugs on the market make it difficult to identify the substances responsible for intoxication cases that turn up at the emergency departments. Once identified, very few data are generally available in the literature about these substances, their metabolism, acute and chronic toxicity, and clinical symptoms that they produce. Moreover, the consumers of new psychoactive substances (NPS) frequently combine the intake different type of drugs resulting in unpredictable serious interactions with related clinical signs difficult to interpret.

In a study reporting 17 intoxication cases produced by consumption of diphenidine and methoxphenidine, common adverse symptoms reported were hypertension (systolic blood pressure $>140 \mathrm{mmHg}$ ), tachycardia (heart rate $>100 \mathrm{bpm}$ ), anxiety, agitation, nystagmus, dilated pupils and muscle rigidity (5). Moreover, altered mental status was sometimes recorded, including modified level of consciousness, hallucinations, confusion, disorientation and dissociation. In another case of acute toxicity associated with the recreational use of methoxphenidine, symptoms such as tachycardia (112 bpm), hypertension (220/125 $\mathrm{mmHg})$, echolalia, confusion, agitation, opisthotonus, nystagmus and amnesia were recognized in the intoxicated patient (6). Moreover, an 
increase of blood creatine kinase $(\max 865 \mathrm{U} / \mathrm{L})$, alanine aminostransferase (72 U/L) and gammaglutamyl transpeptidase (123 U/L) was also reported.

In the present case, the patient showed symptoms such as agitation, disorientation and altered consciousness state. Moreover, tachycardia, increased respiratory rate, miotic pupils and muscular rigidity were reported and blood analysis revealed signs of metabolic acidosis and rabdomiolysis. All the symptoms observed were compatible with the effects induced by dissociative drugs like MXE, ketamine, PCP and the new diphenidine and methoxphenidine drugs $(5,6,13,14)$. The concentration of diphenidine found in plasma $(308 \mathrm{ng} / \mathrm{mL})$ was comparable to those of diphenidine and methoxphenidine in the 17 intoxication cases associated with the consumption of these drugs (2-409 ng/mL; mean: $122 \mathrm{ng} / \mathrm{mL}$; median: $93 \mathrm{ng} / \mathrm{mL}$ ) (5). This concentration is also $4-80$ fold lower than those observed in three fatalities involving methoxphenidine (8). In the patient of the present case, benzodiazepines were administered together with haloperidol for sedation and for the treatment of tachycardia and hypertension. All the other detected substances (excluding methylphenidate and diclazepam) had been used during the therapy in hospital. The simultaneous detection in urine and plasma samples of delorazepam, lormetazepam and lorazepam is compatible with a diclazepam intake, as was demonstrated in a controlled study on diclazepam metabolism (15). In current literature there are very little data on diclazepam levels in biological fluids. The blood concentration found in the presented case $(3.5 \mathrm{ng} / \mathrm{mL})$ is comparable to that registered 3 hours after an oral intake of a $1 \mathrm{mg}$ tablet of diclazepam by a 43 years old male subject (weight 73 $\mathrm{kg}$ ) in a study published by Moosmann et al. (15). Concerning methylphenidate, although the recorded blood concentration $(3 \mathrm{ng} / \mathrm{mL})$ was below the therapeutic levels $(5-60 \mathrm{ng} / \mathrm{mL})(16)$, a possible synergic stimulant effect in combination with diphenidine cannot be excluded. The detection of diclazepam and methylphenidate in the patient's plasma sample suggests that these drugs have most likely been consumed together with diphenidine or within a restricted period of time, potentially influencing and reinforcing their effects. Designer benzodiazepines are often taken as 'self medication' by users of stimulant and hallucinogenic drugs, leading to 'upper downer 
1

2

3

4

5

6

7

8

10

11

12

13

14

15

16

17

18

19

20

21

22

23

24

25

26

27

28

29

30

31

32

33

34

35

36

37

38

39

40

41

42

43

44

45

46

47

48

49

50

51

52

53

54

55

56

57

58

59

60

cycles' (17). Lastly, the presence of diphenidine, together with $\alpha$-PVP, MDPV, methoxetamine, 4fluoroamphetamine and methylone, in the hair sample indicates that the subject had previously been exposed to these drugs in more than one occasion.

In conclusion, diphenidine appears to have acute toxicity similar to that of other dissociative drugs like ketamine, phencyclidine and other new designer drugs, such as methoxethamine and methoxphenidine. Due to the increasing diffusion of these drugs, occasional cases of intoxication from diphenidine consumption are likely to occur, with consequent access to emergency rooms and subsequent hospitalization of the drug users. Despite the lack of data and case reports in the current literature, it is advisable that the whole symptoms are promptly recognized and an adequate treatment is implemented for patients whose intoxication cause cannot be immediately identified. 


\section{References}

[1] Morris H, Wallach J. From PCP to MXE: a comprehensive review of the non-medical use of dissociative drugs. Drug Test Anal 2014; 6:614-632.

[2] Gray NM, Cheng BK. EP patent 0346791, Preparation of "1,2-diarylethylamines for treatment of neurotoxic injury". EU Patent No 0346791A1. 1989, assigned to G.D. Searle \& Co.

[3] Schifano F, Orsolini L, Papanti GD, Corkery GM. Novel psychoactive substances of interest for psychiatry. World Psychiatry 2015; 14:15-26.

[4] Wallach J, Kavanagh PV, McLaughlin G, Morris N, Power JD, Elliot SP, Mercier MS, Lodge D, Morris H, Dempster NM, Brandt SD. Preparation and characterization of the 'research chemical' diphenidine, its pyrrolidine analogue, and their 2,2-diphenylethyl isomers. Drug Test Anal 2014; 7:358-367.

[5] Helander A, Beck O, Bäckberg M. Intoxications by the dissociative new psychoactive substances diphenidine and methoxphenidine. Clin Toxicol 2015; 53:446-453.

[6] Hofer EK, Degrandi C, Müller DM, Zürrer-Härdi U, Wahl S, Rauber-Lüthy C, Ceschi A. Acute toxicity associated with the recreational use of the novel dissociative psychoactive substance methoxphenidine. Clin Toxicol 2014; 52:1288-1291.

[7] Hasegawa K, Wurita A, Minakata K, Gonmori K, Nozawa H, Yamagishi I, Watanabe K, Suzuki O. Postmortem distribution of AB-CHMINACA, 5-fluoro-AMB, and diphenidine in body fluids and solid tissues in a fatal poisoning case: usefulness of adipose tissue for detection of the drugs in unchanged forms. Forensic Toxicol $2015 ; 33: 45-53$.

[8] Elliot SP, Brandt SD, Wallach J, Morris H, Kavanagh PV. First reported fatalities associated with the 'Research Chemical' 2-methoxydiphenidine. J Anal Toxicol 2015; 39:287-293.

[9] Salomone A, Gerace E, Brizio P, Gennaro MC, Vincenti M. A fast liquid chromatography-tandem mass spectrometry method for determining benzodiazepines and analogues in urine. Validation and application to real cases of forensic interest. J Pharm Biomed Anal 2011; 56: 582-591.

[10] Vincenti M, Cavanna D, Gerace E, Pirro V, Petrarulo M, Di Corcia D, Salomone A. Fast screening of 88 pharmaceutical drugs and metabolites in whole blood by ultrahigh-performance liquid chromatography-tandem mass spectrometry. Anal Bioanal Chem 2013; 405:863-879.

[11]Gerace E, Salomone A, Di Corcia D, Mazzucco P, Vincenti M. Postmortem redistribution of triazolam, alprazolam, delorazepam (chlordesmethyldiazepam) and zolpidem in a suicide case. Toxicol Anal Clin 2015; 27:233-238. 
[12] Salomone A, Gazzilli G, Di Corcia D, Gerace E, Vincenti M. Determination of cathinones and other stimulant, psychedelic, and dissociative designer drugs in real hair salmples. Anal Bioanal Chem 2016; 408:2035-2042.

[13] Wood DM, Davies S, Puchnarewicz M, Johnston A, Dargan P I. Acute toxicity associated with the recreational use of the ketamine derivative methoxetamine . Eur J Clin Pharmacol 2012; 68:853-856.

[14] McCarron MM, Schulze BW, Thompson GA, Conder MC, Goetz WA. Acute phencyclidine intoxication: clinical patterns, complications and treatment. Ann Emerg Med 1981; 10:290-297.

[15] Moosmann B, Bisel P, Auwärter V. Characterization of the designer benzodiazepine diclazepam and preliminary data on its metabolism and pharmacokinetics. Drug Test Anal 2014; 6:757-63.

[16] The International Association of Forensic Toxicologists. TIAFT reference blood level list of therapeutic and toxic substances, 2004.

[17] Moosmann B, King LA, Auwärter V. Designer benzodiazepines: a new challenge. World Psychiatry 2015; 14(2):248. 
Figure 1: trend of aspartate aminotransferase (AST), alanine aminotransferase (ALT), creatine kinase (CK) and lactate dehydrogenase (LDH) in patient's blood during the period of admission. 


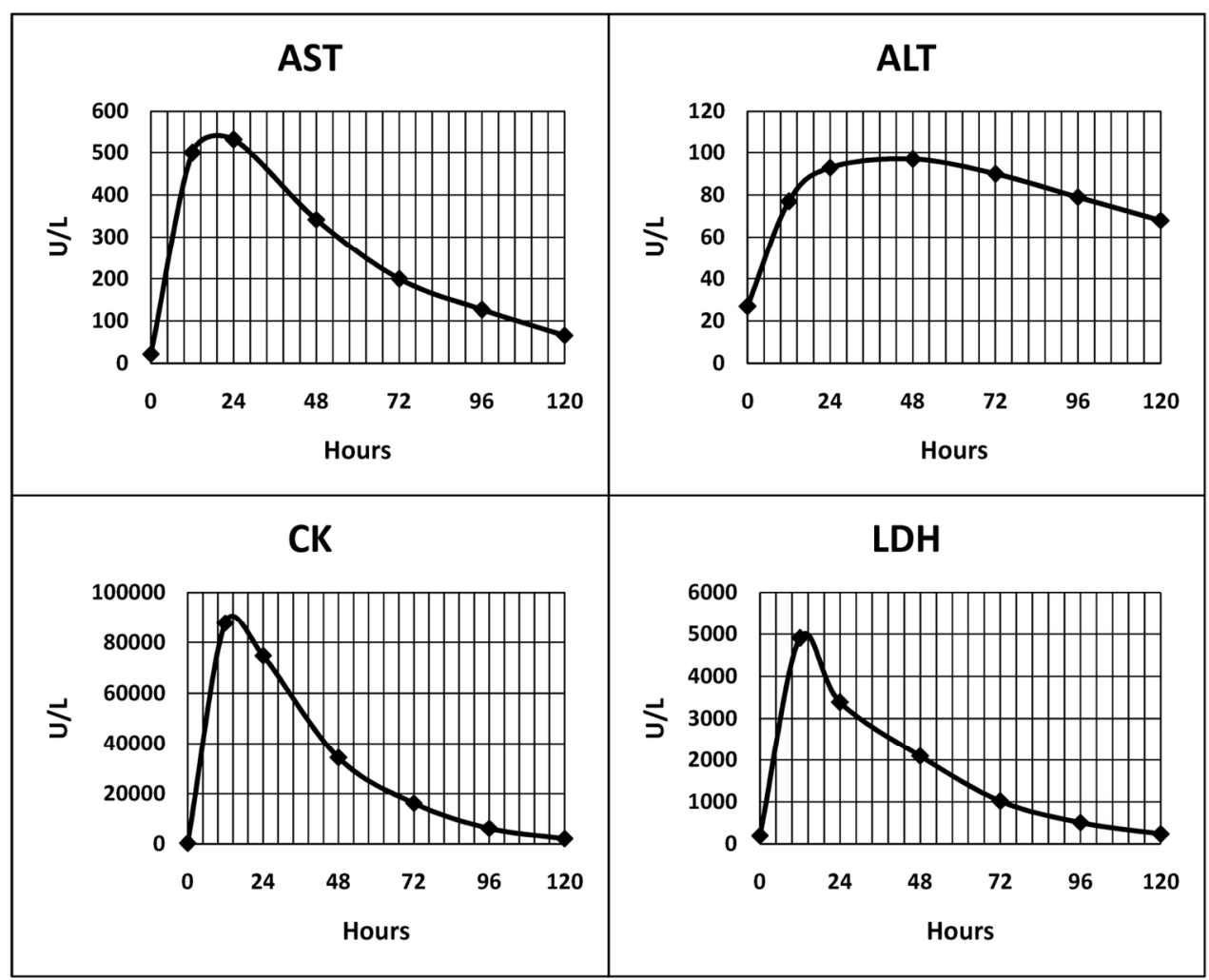

Figure 1

$144 \times 115 \mathrm{~mm}(300 \times 300$ DPI $)$ 
Table 1: analytical findings in plasma and urine samples

\begin{tabular}{lcc}
\hline Analytes & $\begin{array}{c}\text { Plasma } \\
(\mathbf{n g} / \mathbf{m L})\end{array}$ & $\begin{array}{c}\text { Urine } \\
(\mathbf{n g} / \mathbf{m L})\end{array}$ \\
\hline Diphenidine & 308 & 631 \\
Diazepam & 376 & 2.0 \\
Nordiazepam & 7.0 & neg \\
Temazepam & 3.6 & neg \\
Diclazepam & 3.5 & neg \\
Lormetazepam & 2.4 & 345 \\
Delorazepam & 45 & 71 \\
Lorazepam & 5.1 & 212 \\
Midazolam & 214 & 73 \\
Haloperidol & 4.0 & $\mathrm{n} / \mathrm{p}$ \\
Methylphenidate & 3.0 & $<\mathrm{LOQ}$ \\
THC metabolite* & neg & 120 \\
\hline *11-nor-9-carboxy-delta-9-tetrahydrocannabinol \\
n/p: analysis not performed
\end{tabular}

